\title{
Complex Assessment of the Blood Oxidative Metabolism in Qualified Athletes
}

\author{
Konstantin A. Karuzin, $\mathrm{MD}^{1}$; Andrew K. Martusevich, $\mathrm{MD}, \mathrm{PhD}, \mathrm{ScD}^{2 *}$; \\ Alexander S. Samoilov, MD, PhD, ScD ${ }^{1}$ \\ ${ }^{I}$ Federal Medical Biophysical Center named after A.I. Burnazyan, Moscow, Russia \\ ${ }^{2}$ Privolzhsky Research Medical University, Nizhny Novgorod, Russia
}

\begin{abstract}
The purpose of this research was to study the structure of the shifts in the blood oxidative metabolism in professional athletes.

Materials and Methods: The study included 262 highly qualified athletes aged between 19 and 29 years. The control group consisted of healthy untrained volunteers of similar age. In blood plasma, we estimated the levels of 8-isoprostane, ox-LDL, alpha- and beta-carotene, alpha- and gamma-tocopherols, and tissue-specific antioxidants (lycopine, luteine and zeaxantine) and the activity of SOD and GP.

Results: Thus, in qualified athletes, characteristic changes in the state of oxidative metabolism, concerning the components of the pro- and antioxidant systems, were determined; however, the inhomogeneity of these metabolic transformations attracts attention. The revealed regularity allows confirming the previously stated hypothesis about the heterogeneity of shifts in oxidative metabolism in professional athletes, which suggests different approaches to their correction. (International Journal of Biomedicine. 2018;8(3):235-239.)
\end{abstract}

Key Words: oxidative stress • professional athletes • blood oxidative metabolism • antioxidants

\section{Abbreviations}

GPx, glutathione peroxidase; GR, glutathione reductase; LPO, lipid peroxidation; OS, oxidative stress; ox-LDL, oxidized lowdensity lipoprotein; SOD, superoxide dismutase.

\section{Introduction}

In the conditions of disadaptation, including professional sports, there are significant shifts in oxidative metabolism, typically characterized by an intensification of LPO against a background of decreasing antioxidant reserves in organs and tissues..$^{(1-5)}$ The pronounced manifestation of this trend, which is an independent pathogenetic mechanism known as OS, is considered as an independent syndrome. ${ }^{(3-8)}$ Some researchers also give a 3-degree gradation of the severity of this syndrome, ${ }^{(9-12)}$ implying a differentiated approach to

*Corresponding author: Andrew K. Matrusevich, PhD, ScD. Privolzhsky Research Medical University, Nizhny Novgorod, Russia. E-mail: cryst-mart@yandex.ru the evaluation of the pathological state being studied and, consequently, its management.

In view of this circumstance, the possibility and necessity of diagnostics and pathogenetic correction of OS is assumed. ${ }^{(6,10,13-15)}$ In relation to diagnostics, technologies and methods for estimating the shifts in oxidative metabolism have been proposed and are being developed. They are based on the determination of laboratory markers of varying degrees of specificity in biological substrates, the study of spontaneous biochemiluminescence of body fluids and tissues, and the use of modern instrumental techniques (instrumental techniques such as electron paramagnetic resonance and fluorescent probes. and others). ${ }^{(4,9,16,17)}$ It should be noted that the determination of qualitative and quantitative criteria for the diagnosis of the state of pro- and antioxidant systems is necessary not only for the purpose of detecting $\mathrm{OS}^{(2,6,13,16)}$ 
but also for monitoring the adaptive capabilities of individual systems and the organism as a whole, including in sports medicine, adaptation, and environmental physiology. ${ }^{(13,18,19)}$

The second aspect of the problem, pathogenetic correction of OS, is related to the development of measures to correct the disturbances in oxidative metabolism. ${ }^{(10,14,15,20,21)}$ This correction can be performed in two ways: by normalizing metabolism in general and/or by administering into the body natural and synthetic compounds that have antioxidant activity. In this case, the first path is nonspecific, since almost any pharmacological agents can be considered as compounds having indirect antioxidant activity and, therefore, as contributing to the optimization of one or more metabolic components. ${ }^{(6,15,20-22)}$

Taking into account the peculiarities of metabolic processes in professional athletes, who are forced to adapt to intensive regular physical training and to psychoemotional stress during competitive activity, ${ }^{(4,7,11,20,23)}$ determining oxidative metabolism shifts and their severity in professional athletes seems very interesting. At the same time, in the special literature, there is not enough information about the nature of such disturbances, but there are single studies that assume the presence of OS in qualified athletes. ${ }^{(3,8,11,16,21,24)}$

The purpose of this research was to study the structure of the shifts in the blood oxidative metabolism in professional athletes.

\section{Materials and Methods}

The study included 262 highly qualified athletesrepresentatives of cyclic sports (ski races, rowing, cycling, athletics, and orienteering) with a sport title from Candidate for Master of Sport of Russia to Master of Sport of the International Class (Group 1) aged between 19 and 29 years. The control group (Group 2) consisted of healthy untrained volunteers of similar age $(\mathrm{n}=35)$.

The present study was approved by the local Ethics Committee of Federal Medical Biophysical Center named after A.I. Burnazyan (Record No.18 dated 10.12.2015). Written informed consent was obtained from each patient.

The serum level of 8-isoprostane was determined by ELISA using an 8-isoprostane ELISA kit ("USBiological", USA). Quantitative determination of ox-LDL was carried out by ELISA in a microplate format using the automatic immunoassay analyzer "Evolis" (Bio-Rad, Germany-USA) with Biomedica Gruppe reagents. The SOD activity was estimated by inhibiting the auto-oxidation of epinephrine in carbonate buffer at $\mathrm{pH} 10.0$ after the addition of blood hemolysate samples in proportions 1:50, according to the method of M. Sun and S. Zigman (1978). GPx activity was analyzed by measuring the oxidation of reduced glutathione in the presence of t-butylhydroperoxide (Moin 1986), and GR activity by its ability to catalyze NADPH-dependent reduction of oxidized glutathione (Karpischenko AI, 2002). Alpha- and beta-carotene and alpha- and gamma-tocopherol were determined according to the technique of Moisenok et al. (2009). The level of tissue-specific blood antioxidants (lycopene, lutein and zeaxanthin) was determined by chromatographic mass spectrometry, according to A.V. Grigoriev (2005) and N.L. Batsukova \& E.R. Yaremko (2015).

Statistical analysis was performed using the Statistica 6.1 software package (StatSoft Inc, USA). The mean (M), standard error of the mean (SEM), and standard deviation (SD) were calculated. The Shapiro-Wilk test was used in testing for normality. Multiple comparisons were performed with a one-way ANOVA. A probability value of $P<0.05$ was considered statistically significant.

\section{Results and Discussion}

In qualified athletes, the levels of most parameters of the studied metabolic component were significantly different from those in untrained individuals. Thus, in Group 1, the plasma level of 8-isoprostane (Figure 1) was 1.25 times higher than in Group $2(P<0.05)$. Taking into account that the plasma concentration of 8 -isoprostane is considered as an integral laboratory marker of OS, ${ }^{(25)}$ the observed tendency indicates excessive stimulation of free radical oxidation processes induced by intensive physical training.

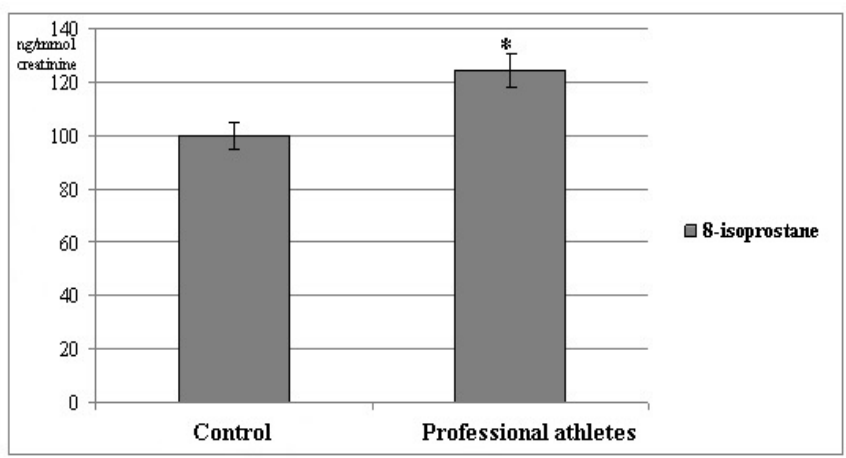

Fig. 1. The plasma level of 8-isoprostane in professional athletes and healthy untrained volunteers $\left(*_{-} P<0.05\right)$.

At the same time, the level of ox-LDL in Group 1 was 16\% lower than in Group $2(P<0.05$, Figure 2$)$, which is apparently related to the predominant effect of the studied factor, not on LPO, but on oxidative damage of other biomacromolecules, in particular, on the oxidative modification of proteins.

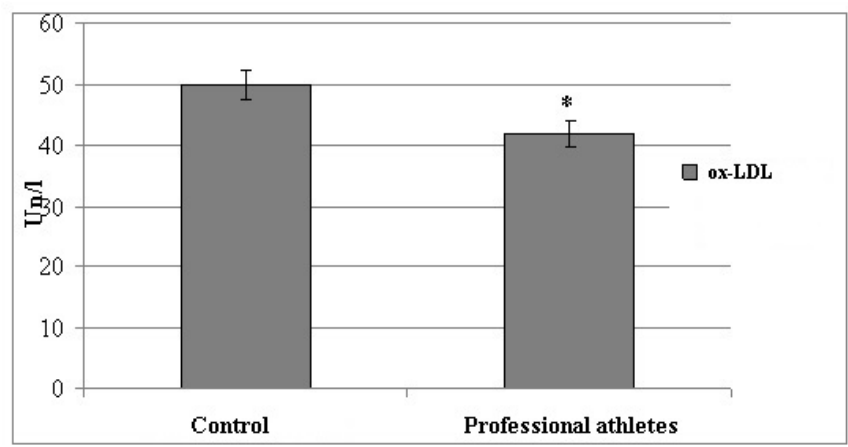

Fig. 2. The plasma level of ox- $L D L$ in professional athletes and healthy untrained volunteers $\left(*_{-} P<0.05\right)$.

This is indirectly evidenced by the character of the shift in SOD 
activity observed in highly trained athletes (Figure 3). Thus, in Group 1, a moderate inhibition of the catalytic properties of this enzyme was found in comparison with Group 2. Changes in the level of this parameter, on the one hand, indicate the active participation of the enzyme in the utilization of the free radicals formed (by removing the superoxide radical anion from the biological fluid), and, on the other hand, can reflect the partial oxidative modification of SOD as a large protein molecule.

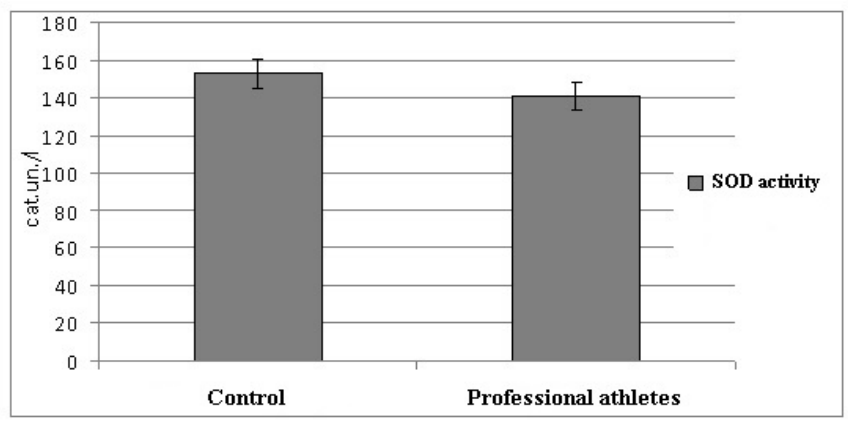

Fig. 3. The catayitic activity of SOD in professional athletes and healthy untrained volunteers.

The pronounced activation of free radical processes in qualified athletes is also evidenced by the dynamics of plasma concentrations of non-tissue-specific, non-enzymatic antioxidants. In particular, the level of alpha and gammatocopherol in Group 1 was significantly lower than in Group 2 (Figure 4). At the same time, this trend is most significant for gamma-tocopherol, the concentration of which in Group 1 was 1.68 times lower than in Group 2, whereas the level of alphatocopherol decreased only 1.23 times ( $P<0.05$ in both cases).

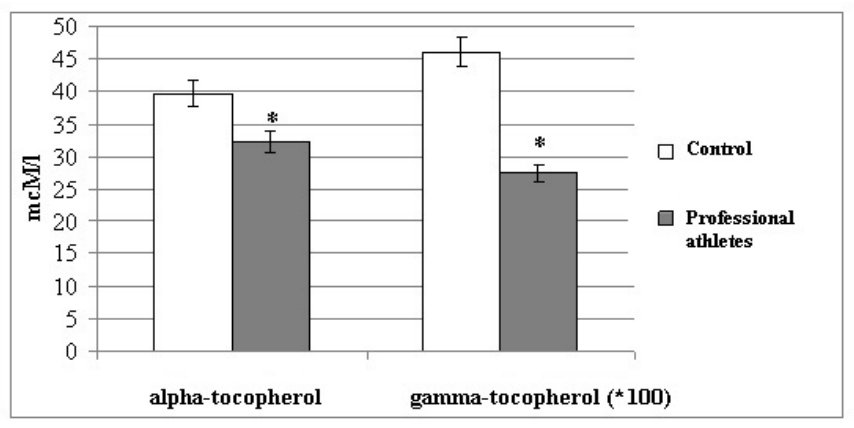

Fig. 4. The plasma level of alpha-tocopherol and gammatocopherol in professional athletes and healthy untrained volunteers $\left(*_{-} P<0.05\right)$.

It should be emphasized that not only does the absolute decrease in the levels of both tocopherols take place, but, taking into account the lipophilic nature of the latter, there is also a decrease in the "plasma vitamin E level/plasma cholesterol level" ratio, which decreased in Group 1 by 1.25 times compared to Group $2(P<0.05)$.

Similar, but less pronounced, changes were recorded for another group of non-enzymatic antioxidants - carotenes (Figure 5). In professional athletes, the plasma level of alpha-carotene decreased more significantly than the plasma concentration of beta-carotene (by 1.3 and 1.1 times, respectively, $P<0.05$ in both cases). This further confirms the deficit of the antioxidant potential, which is formed under the influence of regular, intense physical activity and indicates the development of OS in these conditions.

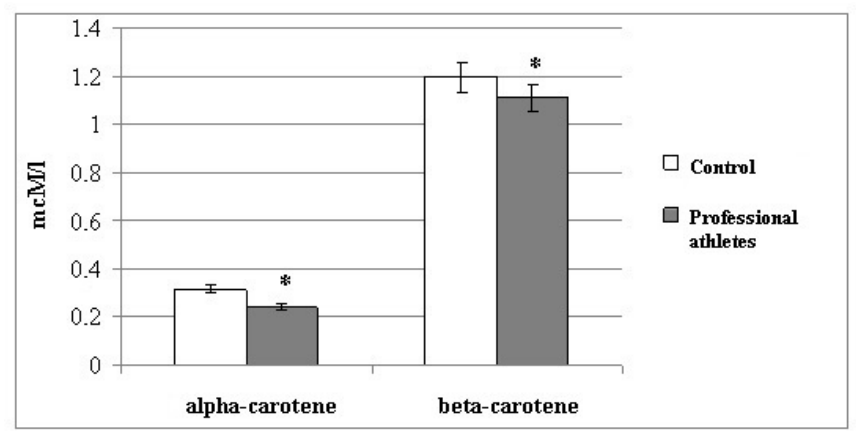

Fig. 5. The plasma level of alpha-carotene and betacarotene in professional athletes and healthy untrained volunteers $\left(*_{-} P<0.05\right)$.

This tendency fully applies to tissue-specific antioxidants also (Figure 6). In particular, the plasma levels of zeaxanthin, lycopene and lutein were significantly reduced in Group 1 compared to Group 2 (up to 1.9 times, $P<0.05$ ).

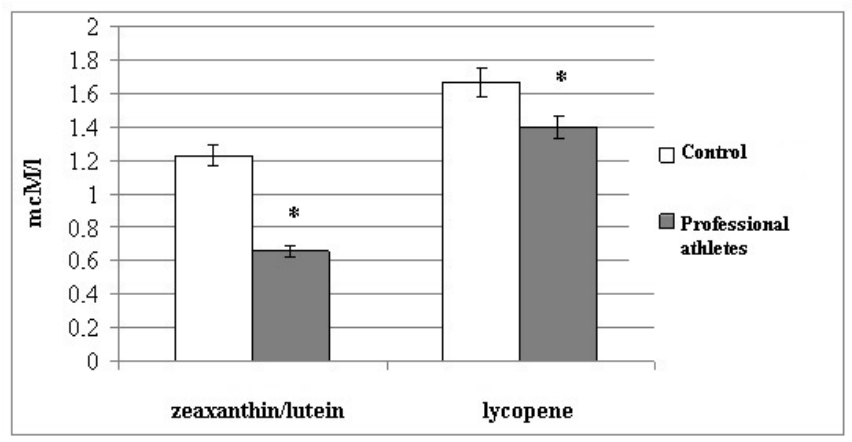

Fig. 6. The plasma level of lycopene, zeaxanthin and lutein in professional athletes and healthy untrained volunteers $\left(*_{-} P<0.05\right)$.

Thus, in qualified athletes, characteristic changes in the state of oxidative metabolism, concerning the components of the pro- and antioxidant systems, were determined. At the same time, the heterogeneity of the nature of the loads used, as well as the presence of individual features of free radical processes, allow one to assume the heterogeneity of their changes under conditions of regular intensive physical training. For a more detailed study of such trends, we used the method of assessing the state of oxidative metabolism, based on a joint examination of the values of parameters characterizing the activity and reserves of pro- and antioxidant systems (Figure 7).

Attention is drawn to the fact that in almost all cases of pairwise comparisons, structural diagrams allow us to distinguish 2 subgroups of athletes, which indicates the expediency of creating two variants of metabolic support oriented to the type of metabolism modification (Figure 7). 


\section{Control}
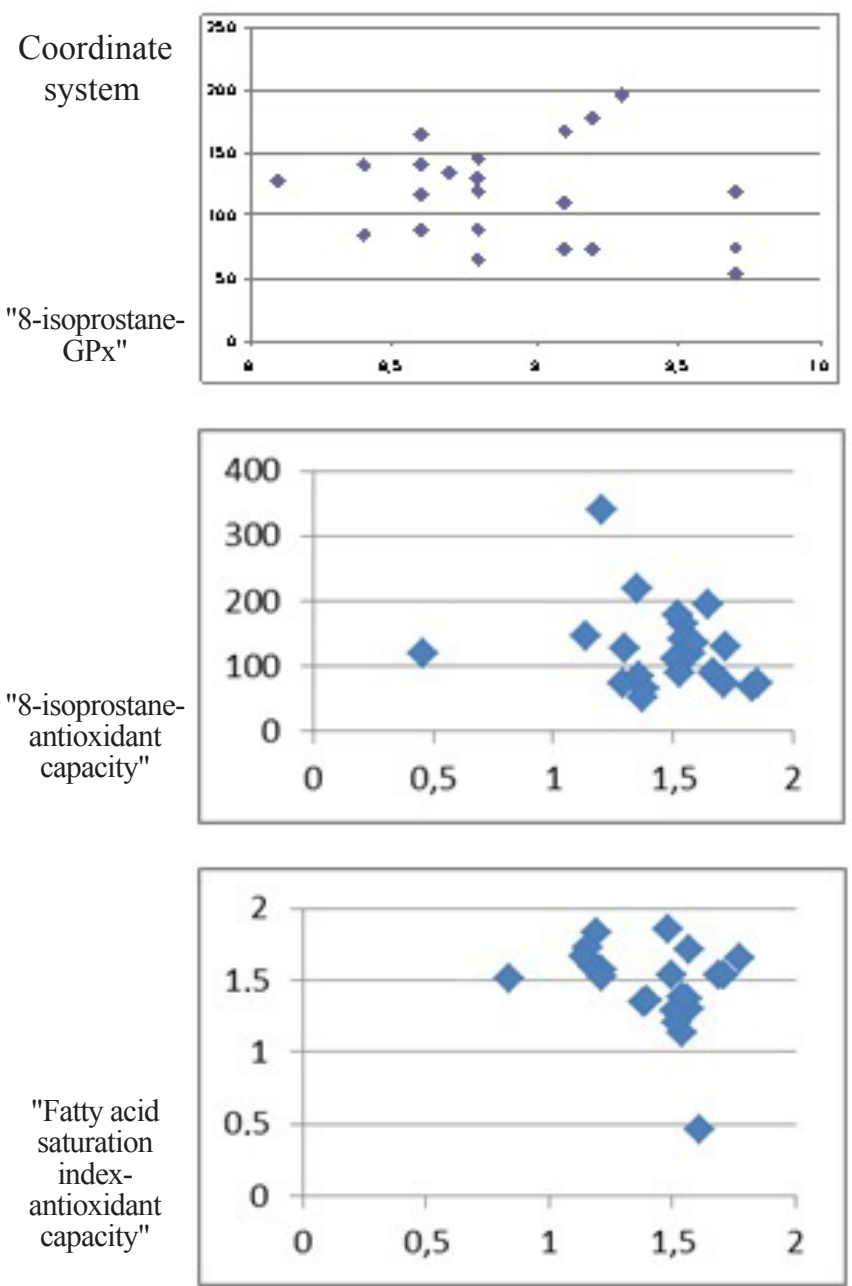

Professional athletes
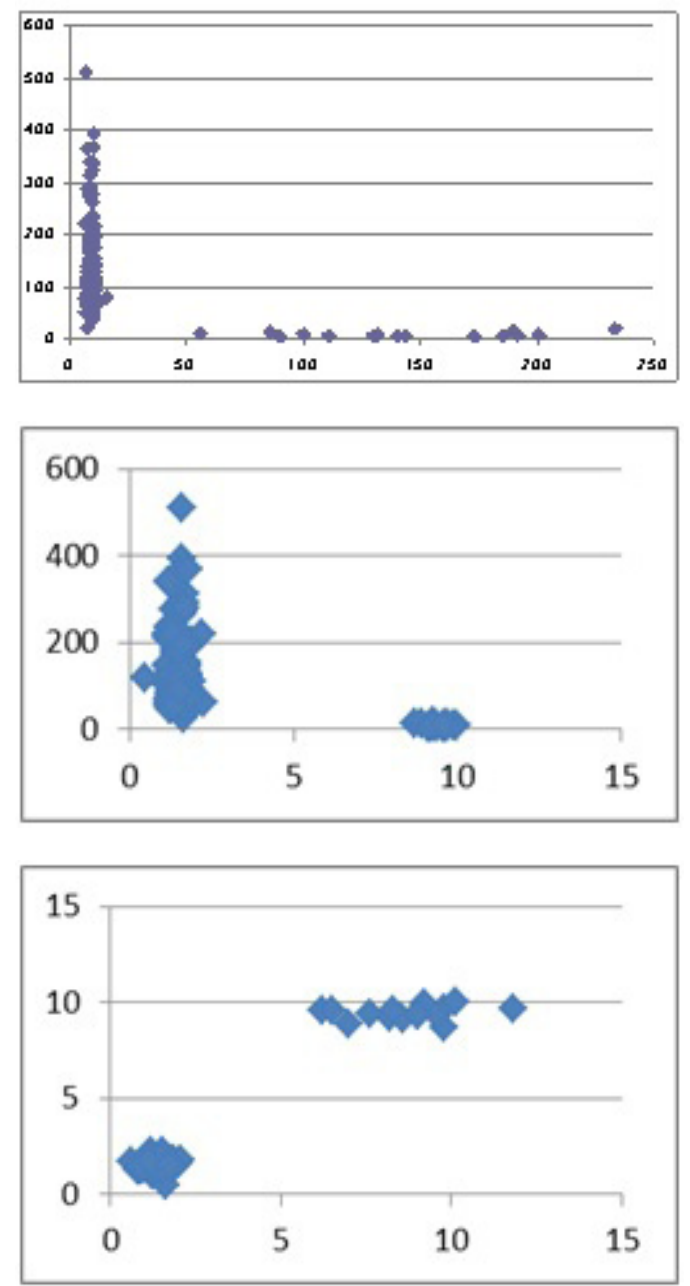

Fig. 7. Two-dimensional comparative analysis of indicators of the state of pro- and antioxidant blood systems in professional athletes and healthy untrained volunteers.

It is interesting that paired comparisons performed between the indices characterizing separately the state of pro- and antioxidant systems, as well as between 2 parameters of one of the listed components of oxidative metabolism, also demonstrate the dichotomous heterogeneity of Group 1 . Thus, the representation of Group 1 in the coordinates "GP activity - SOD activity" allows us to identify 2 subgroups in this group (Figure 8 ).

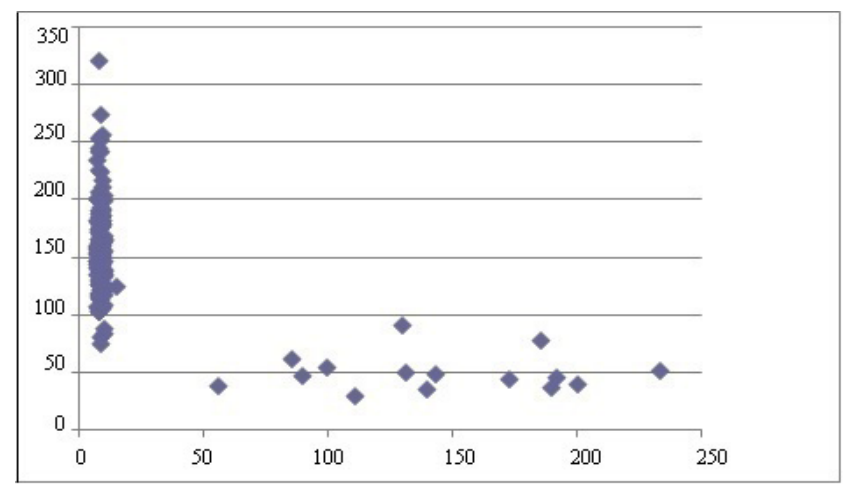

Fig. 8. Distribution of the results of examination of professional athletes in the coordinate system "GPx activity-SOD activity."
Thus, the conducted complex study made it possible to demonstrate the presence of shifts in the blood oxidative metabolism induced by occupations in professional sports. At the same time, the obtained data confirm the formation of OS in qualified athletes; however, the inhomogeneity of these metabolic transformations attracts attention. The revealed regularity allows confirming the previously stated hypothesis about the heterogeneity of shifts in oxidative metabolism in professional athletes, which suggests different approaches to their correction. Further research in this area can be aimed at developing the OS management, taking into account the type of reactions of the blood oxidative metabolism in conditions of regular and intense physical activity.

\section{Competing interests}

The authors declare that they have no competing interests.

\section{References}

1. Zborovskaia IA, Bannikova MV. [The body's antioxidant system, its significance in metabolism. Clinical aspects]. Vestn 
Ross Akad Med Nauk;1995;(6):53-60. [Article in Russian] 2. Statsenko EA. [Characteristics of lipid peroxidation and markers of endogenous intoxication in monitoring physical loads during rower training]. Vopr Kurortol Fizioter Lech Fiz Kult. 2011;(3):41-5. [Article in Russian]

3. Aguiló A, Tauler P, Fuentespina E, Tur JA, Córdova A, Pons A. Antioxidant response to oxidative stress induced by exhaustive exercise. Physiol Behav. 2005;84(1):1-7.

4. Margonis K, Fatouros IG, Jamurtas AZ, Nikolaidis MG, Douroudos I, Chatzinikolaou A, et al. Oxidative stress biomarkers responses to physical overtraining: implications for diagnosis. Free Radic Biol Med. 2007;43(6):901-10.

5. Vider J, Lehtmaa J, Kullisaar T, Vihalemm T, Zilmer K, Kairane C, Landõr A, Karu T, Zilmer M. Acute immune response in respect to exercise-induced oxidative stress. Pathophysiology. 2001;7(4):263-270.

6. Kalinkin LA, Statsenko EA, Ponomareva AG, Morozov VN, Kutnyakhova LV, Krivoshchapov MV, et al. [Oxidative stress in physical training: methods of diagnosis and correction of antioxidant status]. Bulletin of Sport Science. 2014;2:3135. [Article in Russian]

7. Dreissigacker U, Wendt M, Wittke T, Tsikas D, Maassen N. Positive correlation between plasma nitrite and performance during high-intensive exercise but not oxidative stress in healthy men. Nitric Oxide. 2010 Sep 15;23(2):128-35. doi: 10.1016/j.niox.2010.05.003.

8. Steinberg J, Gainnier M, Michel F, Faucher M, Arnaud C, Jammes Y. The post-exercise oxidative stress is depressed by acetylsalicylic acid. Respir Physiol Neurobiol. 2002 Apr;130(2):189-99.

9. Peretyagin SP, Martusevich AK, Vanin AF. [Molecularcellular mechanisms of transformation of homeostasis of biosystems with reactive oxygen species and nitrogen]. Medical Almanac. 2013; 3: 80-81. [Article in Russian]

10. Morillas-Ruiz JM1, Villegas García JA, López FJ, Vidal-Guevara ML, Zafrilla P. Effects of polyphenolic antioxidants on exercise-induced oxidative stress. Clin Nutr. 2006;25(3):444-53.

11. Pepe H, Balci SS, Revan S, Akalin PP, Kurtoğlu F. Comparison of oxidative stress and antioxidant capacity before and after running exercises in both sexes. Gend Med. 2009;6(4):587-95. doi: 10.1016/j.genm.2009.10.001.

12. Veskoukis AS, Nikolaidis MG, Kyparos A, Kouretas D. Blood reflects tissue oxidative stress depending on biomarker and tissue studied. Free Radic Biol Med. 2009;47(10):1371-4. doi: 10.1016/j.freeradbiomed.2009.07.014.

13. Kukes VT, Gorodetsky VV. [Sport pharmacology: achievements, problems, and prospects]. Sports Medicine: Research and Practice. 2010;1(1):12-15. [Article in Russian] 14. Cholewa J, Poprzęcki S, Zajac A, Waskiewicz Z. The influence of vitamin $\mathrm{C}$ on blood oxidative stress parameters in basketball players in response to maximal exercise. Science \& Sports. 2008;23(3-4):176-182.

15. McAnulty SR, McAnulty LS, Nieman DC, Morrow JD, Shooter LA, Holmes S, Heward C, Henson DA. Effect of alpha-tocopherol supplementation on plasma homocysteine and oxidative stress in highly trained athletes before and after exhaustive exercise. J Nutr Biochem. 2005;16(9):530-7.

16. Statsenko EA, Serezhkina TV, Korolevich MP, Al'kevich EV. [Laboratory methods for assessing the state of the antioxidant system of the body in the process of sports]. Meditsinskii Zhurnal. 2008;2:73-75. [Article in Russian].

17. Wagner KH, Reichhold S, Hölzl C, Knasmüller S, Nics L, Meisel M, Neubauer O. Well-trained, healthy triathletes experience no adverse health risks regarding oxidative stress and DNA damage by participating in an ultra-endurance event. Toxicology. 2010;278(2):211-6. doi: 10.1016/j.tox.2009.09.006. 18. Solodkov AS, Levshin IV, Polikarpochkin AN, Mjasnikov AA. [Physiological mechanisms and laws of functional recovery processes in sports in the various climatic and geographical conditions]. Human Ecology. 2010;6:36-41. [Article in Russian].

19. Klehe UC, Anderson N. Working hard and working smart: motivation and ability during typical and maximum performance. J Appl Psychol. 2007;92(4):978-92.

20. Pfeiffer JM, Askew EW, Roberts DE, Wood SM, Benson JE, Johnson SC, Freedman MS. Effect of antioxidant supplementation on urine and blood markers of oxidative stress during extended moderate-altitude training. Wilderness Environ Med. 1999 Summer;10(2):66-74.

21. Sun L, Shen W, Liu Z, Guan S, Liu J, Ding S. Endurance exercise causes mitochondrial and oxidative stress in rat liver: effects of a combination of mitochondrial targeting nutrients. Life Sci. 2010;86(1-2):39-44. doi: 10.1016/j.lfs.2009.11.003.

22. Zaitsev VG, Ostrovskii OV, Zakrevskii VI. [Classification of the direct-acting antioxidants based on a relationship between chemical structure and target]. Eksperimental'naia i Klinicheskaia Farmakologiia. 2003;66(4):66-70. [Article in Russian].

23. Hilfiker R, Hübner K, Lorenz T, Marti B. Effects of drop jumps added to the warm-up of elite sport athletes with a high capacity for explosive force development. J Strength Cond Res. 2007;21(2):550-5.

24. Leelarungrayub D, Saidee K, Pothongsunun P, Pratanaphon S, YanKai A, Bloomer RJ. Six weeks of aerobic dance exercise improves blood oxidative stress status and increases interleukin-2 in previously sedentary women. J Bodyw Mov Ther. 2011;15(3):355-62. doi: 10.1016/j.jbmt.2010.03.006.

25. Kostikas K, Papatheodorou G, Psathakis K, Panagou P, Loukides S. Oxidative stress in expired breath condensate of patients with COPD. Chest 2003;124(4):1373-80. 